\title{
Immune and inflammatory gene signature in rat cerebrum in subarachnoid hemorrhage with microarray analysis
}

\author{
CHU-I LEE ${ }^{*}$, AN-KUO CHOU ${ }^{2,3^{*}}$, CHING-CHIH LIN ${ }^{4}$, CHIA-HUA CHOU $^{4}$, JOON-KHIM LOH ${ }^{5}$, \\ ANN-SHUNG LIEU ${ }^{5}$, CHIH-JEN WANG ${ }^{5}$, CHI-YING F. HUANG ${ }^{6}$, \\ SHEN-LONG HOWNG ${ }^{2,5}$ and YI-REN HONG ${ }^{2,4}$
}

\author{
${ }^{1}$ Department of Medical Laboratory Science and Biotechnology, Fooyin University, Kaohsiung; \\ ${ }^{2}$ Graduate Institute of Medicine, Kaohsiung Medical University, Kaohsiung; ${ }^{3}$ Department of Anesthesiology, \\ Chang Gung Memorial Hospital, Kaohsiung; ${ }^{4}$ Department of Biochemistry, Faculty of Medicine, College of \\ Medicine, Kaohsiung Medical University, Kaohsiung; ${ }^{5}$ Department of Neurosurgery, Kaohsiung Medical University \\ Hospital, Kaohsiung; ${ }^{6}$ Institute of Clinical Medicine, National Yang-Ming University, Taipei, Taiwan, R.O.C.
}

Received July 12,2011; Accepted September 29, 2011

DOI: $10.3892 / \mathrm{mmr} .2011 .614$

\begin{abstract}
Cerebral vasospasm following subarachnoid hemorrhage $(\mathrm{SAH})$ has been studied in terms of a contraction of the major cerebral arteries, but the effect of cerebrum tissue in $\mathrm{SAH}$ is not yet well understood. To gain insight into the biology of SAH-expressing cerebrum, we employed oligonucleotide microarrays to characterize the gene expression profiles of cerebrum tissue at the early stage of SAH. Functional gene expression in the cerebrum was analyzed $2 \mathrm{~h}$ following stage 1-hemorrhage in Sprague-Dawley rats. mRNA was investigated by performing microarray and quantitative real-time PCR analyses, and protein expression was determined by Western blot analysis. In this study, 18 upregulated and 18 downregulated genes displayed at least a 1.5-fold change. Five genes were verified by real-time PCR, including three upregulated genes [prostaglandin E synthase (PGES), CD14 antigen, and tissue inhibitor of metalloproteinase 1 (TIMP1)] as well as two downregulated genes [KRAB-zinc finger protein-2 (KZF-2) and $\gamma$-aminobutyric acid $B$ receptor 1 (GABA B receptor)]. Notably, there were functional implications for the three upregulated genes involved in the inflammatory SAH process. However, the mechanisms leading to decreased KZF-2
\end{abstract}

Correspondence to: Dr Yi-Ren Hong, Graduate Institute of Biochemistry, Kaohsiung Medical University, No. 100, Shih-Chuan 1st Road, Kaohsiung 807, Taiwan, R.O.C.

E-mail: m835016@cc.kmu.edu.tw

Dr Shen-Long Howng, Department of Neurosurgery, Kaohsiung Medical University Hospital, No. 100, Shih-Chuan 1st Road, Kaohsiung 807, Taiwan, R.O.C.

E-mail: slhowng@cc.kmu.edu.tw

*Contributed equally

Key words: subarachnoid hemorrhage, microarray, inflammation, tissue inhibitor of metalloproteinase 1 , rat and GABA B receptor expression in SAH have never been characterized. We conclude that oligonucleotide microarrays have the potential for use as a method to identify candidate genes associated with SAH and to provide novel investigational targets, including genes involved in the immune and inflammatory response. Furthermore, understanding the regulation of MMP9/TIMP1 during the early stages of SAH may elucidate the pathophysiological mechanisms in SAH rats.

\section{Introduction}

Subarachnoid hemorrhage ( $\mathrm{SAH})$ is a complex disease associated with high mortality and high morbidity and has no effective therapy. SAH can be caused by a ruptured aneurysm, leaking arteriovenous malformation or head trauma. Brain cells in this area may be irritated and damaged as blood spills into the subarachnoid space. Accumulating evidence supports the role of free radical formation and perturbations in nitric oxide, endothelin-1 and nicotinamide adenine dinucleotide phosphate (NADPH) oxidase activities in the cerebral basal artery, which are mediators of vasoconstriction in vasospasm (1-3). However, pathophysiological studies evaluating other brain tissues and their hemorrhagic molecular mechanisms of acute SAH-induced injury are rare.

Recently, complementary DNA (cDNA) or oligonucleotide microarray hybridization has made possible a broad survey of all the functional categories of genes, revealing their differential expression patterns in pathological tissue from various brain diseases, including the human middle cerebral artery following cerebral ischemia (4), brain tissue in intracerebral hemorrhage (5) and cerebral arteries following subarachnoid hemorrhage (6).

Currently, one key homeostatic mechanism of the brain in tissue repair is maintained through the production of tissue inhibitor of metalloproteinases (TIMPs) $(7,8)$. An imbalance of matrix metalloproteinase (MMP)/TIMP regulation has been implicated in a number of inflammatory diseases of the central nervous system $(9,10)$. Increased expression of 
MMP9 is intimately involved in the mechanisms of SAH (11). Therefore, we hypothesized that MMP9 and TIMP1 are likely to play significant roles in the repair mechanisms of cerebrum$\mathrm{SAH}$, particularly during acute phases of SAH.

In this study, we demonstrate the potential of oligonucleotide microarray as a method to identify candidate genes associated with $\mathrm{SAH}$, and to provide novel investigational targets including genes involved in the immune and inflammatory response. Targeting these mediators of systemic inflammation associated with SAH is a promising therapeutic strategy for the future.

\section{Materials and methods}

SAH rat model. A total of 31 male Sprague-Dawley rats (300-400 g) were divided into a normal saline-operated group $(\mathrm{S})$, an SAH group $(\mathrm{H})$ and a normal group $(\mathrm{C})$. We used 8 normal control rats [two for the microarray experiment, three for the reverse transcription polymerase chain reaction (RT-PCR) and three for the Western blot analyses], 11 sham-operated rats (two for the microarray experiment, three for the real-time PCR, three for the RT-PCR and three for the Western blot analyses), and 12 rats for the SAH model (three for the microarray experiments, three for the real-time PCR, three for the RT-PCR and three for the Western blot analyses). All rats were anesthetized with ketamine [100 mg/kg intraperitoneally (i.p.)] and xylazine (10 mg/kg i.p.) and the animals were allowed to breathe spontaneously. Following anesthesia, the femoral artery was exposed and catheterized with a PE-50 catheter to allow measurement of blood gas values, blood $\mathrm{pH}$ and continuous recording of mean arterial blood pressure. The physiological values immediately following SAH were as follows: $36.5 \pm 0.6^{\circ} \mathrm{C}$ body temperature, $7.33 \pm 0.05 \mathrm{pH}, 143.2 \pm 19.3 \mathrm{PaO}_{2}$ and $40.3 \pm 7.6 \mathrm{PaCO}_{2}$ (values are the mean $\pm \mathrm{SD}, \mathrm{n}=5$ ). Aided by a surgical microscope, the atlantooccipital membrane was tapped carefully into the cisterna magna with a 27 -gauge needle. After $0.3 \mathrm{ml}$ of cerebrospinal fluid was aspirated, an equal amount of autologous blood from the femoral artery was injected during a period exceeding $3 \mathrm{~min}$. The rats were then placed in a head-down prone position at a 30 -degree angle for $30 \mathrm{~min}$ to hold the blood in the basal cisterns. Sham-control rats were injected with $0.9 \%$ sterile $\mathrm{NaCl}$ solution instead of blood. Rats were sacrificed at $2 \mathrm{~h}$ for microarray, real-time, and RT-PCR assay and at $24 \mathrm{~h}$ for Western blot analysis following SAH. The studies were reviewed and approved by the Institutional Animal Care and Use Committee of Kaohsiung Medical University.

Rat brain harvesting. At 2 or $24 \mathrm{~h}$ following $\mathrm{SAH}$, all rats from each group were anesthetized with ketamine $(100 \mathrm{mg} / \mathrm{kg}$ i.p.) and xylazine (10 mg/kg i.p.). The chest was opened and the aorta was cannulated with a blunted 23-gauge needle through the left ventricle. An incision was made in the right atrium to allow for outflow of perfusion solutions. A total of $20 \mathrm{ml}$ of normal saline was infused, followed by $4 \%$ paraformaldehyde for $10 \mathrm{~min}$. All perfusates were delivered at 60 to $80 \mathrm{~mm} \mathrm{Hg}$. The cerebrum was then harvested and stored in a refrigerator at $-70^{\circ} \mathrm{C}$.

RNA isolation and microarray analysis. RNA preparation and analysis were performed according to Affymetrix's protocol. The precipitated products were treated with DNase (Promega,
Table I. Sequences for primers used in real-time PCR amplification.

\begin{tabular}{|c|c|}
\hline Gene name & Primers (forward and reverse) \\
\hline $\begin{array}{l}\text { Prostaglandin E } \\
\text { synthase }\end{array}$ & $\begin{array}{l}\text { F: GCGTTGAAACGTGGAGGT } \\
\text { R: ATCGTCTCCATGTCGTTGC }\end{array}$ \\
\hline CD14 & $\begin{array}{l}\text { F: AAAGAAACTGAAGCCTTTCTCG } \\
\text { R: AGCAACAAGCCGAGCATAA }\end{array}$ \\
\hline $\begin{array}{l}\text { Protein tyrosine, } \\
\text { phosphatase receptor } \\
\text { type, } \mathrm{J}\end{array}$ & $\begin{array}{l}\text { F: GCTTCCTTTCCTGGGTCAG } \\
\text { R: GACATTTGTCACTCGGAAGTCA }\end{array}$ \\
\hline TIMP1 & $\begin{array}{l}\text { F: CAGCAAAAGGCCTTCGTAAA } \\
\text { R: TGGCTGAACAGGGAAACACT }\end{array}$ \\
\hline TNF receptor, $12 \mathrm{a}$ & $\begin{array}{l}\text { R: TTGCACAAGGGAATCTCTTGCT } \\
\text { R: GGTGGAACCCAGTCTTGTGTCT }\end{array}$ \\
\hline TIS11 & $\begin{array}{l}\text { F: GAGCAGGGCAGGAGTCAG } \\
\text { R: TTTGTCCAGTTCCCGTTTGT }\end{array}$ \\
\hline Cortistatin & $\begin{array}{l}\text { F: CCAGGACAGTGTGCAGGAT } \\
\text { R: CCAGGCAAGGAAAGTCAGAA }\end{array}$ \\
\hline Fibrinogen-like 2 & $\begin{array}{l}\text { F: GCAAGGATGAGGCTTCCTG } \\
\text { R: CCCTTCAGTCAGGTTGTGCT }\end{array}$ \\
\hline $\mathrm{KZF}-2$ & $\begin{array}{l}\text { F: TCCATTTCTGTTGTCCGATACA } \\
\text { R: AGAAATCAATGGCCACATCC }\end{array}$ \\
\hline GABA B receptor & $\begin{array}{l}\text { F: CTCTTCTCTGATCCCCGTCTT } \\
\text { R: TATACTGCACGCCGTTCTGA }\end{array}$ \\
\hline$\beta$-actin & $\begin{array}{l}\text { F: CCCGCGAGTACAACCTTCT } \\
\text { R: CGTCATCCATGGCGAACT }\end{array}$ \\
\hline
\end{tabular}

Madison, WI, USA) and further purified with the RNeasy Mini Kit (Qiagen, Valencia, CA, USA). The RNA from each sample was collected into a total of $10 \mu \mathrm{g}$ of RNA. The integrity of the RNA from the pooled samples was determined using Spectra Max Plus (Molecular Devices) and the ratio of A260/A280 was from 1.9 to 2.1. mRNA was then extracted from the total RNA samples using the Oligotex mRNA Kit (Qiagen). The cDNA was prepared from mRNA using the GeneChip ${ }^{\circledR}$ Expression 3'-Amplification Reagents Two-Cycle cDNA Synthesis Kit (Affymetrix, P/N 900432), with the exception that the primer used for the reverse transcription reaction was a modified T7 primer with 24 thymidines. Following this, labeled cRNA was synthesized from the cDNA using the Bioarray High Yield RNA Transcript Labeling Kit (Affymetrix, P/N 900182) according to the manufacturer's instructions. Fragmentation of biotinylated cRNA (15 $\mu \mathrm{g})$ by GeneChip Sample Cleanup Module (Affymetrix, P/N 900371), protocols and reagents for hybridization, washing, and staining were all performed following instructions provided by Affymetrix (http://www. affymetrix.com/support/technical/manuals.affx). Prior to hybridization of the Affymetrix Human Genome U133A Array, labeled cRNA was hybridized to the Affymetrix GeneChip Test 3 Array to verify quality.

Data analysis and clustering algorithm. The microarray data were analyzed using the GeneSpring ${ }^{\circledR} 6.2$ software (Silicon 
Genetics, Redwood City, CA, USA). Sequences on Affymetrix chips were generally represented by an average of 16 perfect matched (PM) probe sets and corresponding mismatch (MM) sequences as false-positive control and nonspecific hybridization. Absolute intensity statistics were based on feature intensities, and corresponding standard deviations were provided in the microarray chip-generated CEL files. To evaluate gene expression patterns, hierarchical clustering using the Pearson's correlation metric and average linkage was performed. Data sets from two normal (C), two saline-operated (S) and three SAH $(\mathrm{H})$ rats were used for this analysis. Genes showing fold change (FC) values $>1.5$ or $<-1.5$ and unpaired t-test $p$-values of $<0.05$ between $\mathrm{H}$ specimens and $\mathrm{S}$ specimens were defined as denoting a significant FC. Two additional criteria were performed on the list. i) The significantly differentially expressed genes $(\mathrm{p}<0.05)$ between $\mathrm{C}$ and $\mathrm{S}$ specimens were removed. ii) Of the genes that were differentially expressed $>25 \%$, two S genes were removed.

Real-time PCR. A total of 10 genes were selected for quantitative expression analysis, and $2 \mu \mathrm{g}$ total RNA was reverse transcribed into single-strand cDNA using random primers. cDNA products were amplified using gene-specific primers (Table I) and real-time PCR was performed with an ABI Prism 7300 Sequence Detection System and 2X SYBR Green PCR Master mix (Applied Biosystems, CA, USA). Cycling parameters were as follows: $50^{\circ} \mathrm{C}$ for $2 \mathrm{~min}, 95^{\circ} \mathrm{C}$ for $10 \mathrm{~min}, 95^{\circ} \mathrm{C}$ for $15 \mathrm{sec}$ and then $60^{\circ} \mathrm{C}$ for $1 \mathrm{~min}$ (40 cycles). Each sample was analyzed three times, each time in triplicate and each experiment was performed three times using independent rat total RNA. $\beta$-actin was used as an internal control.

$R T-P C R$. Total RNA was prepared using TRIzol (Qiagen). An aliquot $(1 \mu \mathrm{g})$ of RNA was reverse-transcribed by MMLV-RT using oligo-dT as the primer (Qiagen). The reaction was carried out at $42^{\circ} \mathrm{C}$ for $60 \mathrm{~min}$ in a $20-\mu \mathrm{l}$ volume. The product was diluted to $100 \mu \mathrm{l}$ with water and an aliquot $(1 \mu \mathrm{l})$ was used as the template for PCR. A final volume of $20 \mu \mathrm{l}$ containing $1 \mathrm{X}$ amplification buffer, $200 \mu \mathrm{M}$ each deoxyribonucleotide triphosphate (dNTP) and 0.5 unit of Taq DNA polymerase, $2 \mu \mathrm{M}$ of each primer and $1 \mu \mathrm{l}$ of cDNA solution was performed. Temperatures and time schedules were: initial denaturation for 5 min at $95^{\circ} \mathrm{C}, 30$ cycles with denaturation at $95^{\circ} \mathrm{C}$ for $60 \mathrm{sec}$, annealing at $59-64^{\circ} \mathrm{C}$ for $60-120 \mathrm{sec}$, extension at $72^{\circ} \mathrm{C}$ for $120 \mathrm{sec}$ and final extension at $72^{\circ} \mathrm{C}$ for $7 \mathrm{~min}$. The primer used for amplification included MMP2 (436 bp), F: CCACAT TCTGGCCTGAGCTCCC; R: GATTTGATGCTTCCAAA CTTCA and MMP9 (193 bp), F: AGGCTACAGCTTTGCTG CCCC; R: GCTGCTTCTGAAGCATCAGCA. The primers used for amplifying TIMP1 were the same as those used in real-time PCR. PCR products were run on a $2 \%$ agarose gel and stained with ethidium bromide.

Protein extraction and Western blot analysis. Total proteins were extracted from cerebrum tissues and homogenized in buffer [10 mM 4-(2-hydroxyethyl)-1-piperazineethanesulfonic acid (HEPES), $1 \mathrm{mM}$ ethylenediaminetetraacetic acid (EDTA), $1 \mathrm{mM}$ ethylene glycol tetraacetic acid (EGTA), $150 \mathrm{mM} \mathrm{NaCl}$, $50 \mathrm{mM} \mathrm{NaF}, 10 \mathrm{mM}$ sodium pyrophosphate, $1 \mathrm{mM}$ sodium orthovanadate, $10 \mathrm{mg} / \mathrm{ml}$ leupeptin, $1 \mathrm{mg} / \mathrm{ml}$ aprotinin and $1 \mathrm{mg} / \mathrm{ml}$ antipain]. The homogenates were centrifuged at
$1500 \mathrm{x} \mathrm{g}$ for $10 \mathrm{~min}$ at $4^{\circ} \mathrm{C}$, followed by a second centrifugation of the supernatant at $12,000 \mathrm{x}$ g for $10 \mathrm{~min}$. The supernatant was then used for the analysis. Protein samples were separated by $12 \%$ sodium dodecyl sulfate polyacrylamide gel electrophoresis (SDS-PAGE) and transferred onto Hybond-ECL membranes (Amersham). These were saturated with 5\% nonfat milk in PBS and $0.1 \%$ Tween-20 for $1 \mathrm{~h}$ at room temperature and then incubated with a mouse anti-human TIMP1 monoclonal antibody (dilution 1:300) (Chemicon; Temecula, CA) in the same solution for $2 \mathrm{~h}$. The membranes were rinsed in phosphate buffered saline (PBS) containing $0.1 \%$ Tween-20 and incubated for $1 \mathrm{~h}$ in the milk buffer with a peroxidase-coupled sheep antimouse IgG (dilution 1:3,000) (Amersham). Immunoreaction signals were visualized with enhanced chemiluminescence (ECL-PLUS, Amersham). $\beta$-actin (dilution 1:2,000) (rabbit $\beta$-actin antibody, Sigma) was used to normalize the immunoreactivity of TIMP1 in each sample.

\section{Results}

Differential expression of genes in the SAH cerebrum. To investigate genes involving SAH, we used Affymetrix oligonucleotide microarray to analyze the differential expression pattern of 19,174 genes between two normal (C), two salineoperated control (S) and three SAH (H) samples (Fig. 1A). Based on the selection criteria, 36 out of 19,174 genes were considered to be deregulated genes, and were separated into three clusters, C, H and S (Fig. 1B). Those in cluster $\mathrm{H}$ were all upregulated compared to all of the genes in cluster $\mathrm{S}$ and were also downregulated, indicating that our microarray analysis was an effective approach to identify those putatively deregulated genes for their possible involvement in this SAH. The 18 genes that were significantly upregulated in SAH cerebrum including prostaglandin E synthase (PGES), CD14 antigen, TIMP1 and TNF superfamily 2a (Table II), while 18 genes were significantly downregulated in SAH cerebrum (Table III). The ontology of the 36 genes was further used to classify categories including immune and inflammatory factors, cell surface molecules, synaptic transmission proteins, metabolism and unknown functions. Notably, the expression of genes involved in the regulation of the immune and inflammatory response (PGES, CD14 antigen, TIMP1, TNF receptor superfamily member 12a, TIS11 complete cds and fibrinogen-like 2) were increased and the expression of the genes for synaptic transmission ( $\gamma$-aminobutyric acid B receptor 1), chloride homeostasis (chloride channel 3) and protein metabolism/turnover (KRABzinc finger protein KZF-2 and cytochrome P450-like protein) were reduced.

Validation of 10 deregulated genes in SAH cerebrum specimens by real-time PCR. Eight potentially upregulated genes including, PGES, CD14 antigen, protein tyrosine phosphatase receptor type J, TIMP1, TNF receptor superfamily member 12a, TIS11 complete cds, cortistatin and fibrinogen-like 2, and two downregulated genes, KRAB-zinc finger protein KZF-2 (KZF-2) and GABA B receptor, were selected for confirmation. Consistent with the Affymetrix oligonucleotide microarray analysis, the upregulation of PGES, CD14 antigen and TIMP1, and downregulation of KZF-2 and GABA B receptor were also observed in SAH cerebrum specimens, 
Table II. Differentially expressed upregulated genes in the subarachnoid hemorrage cerebrum.

Accession no.

Gene description

Fold change

Immune and inflammation

NM_053819

Tissue inhibitor of metalloproteinase 1

2.6

AF280967

Prostaglandin E synthase

2.3

AB025017

Rattus norvegicus gene for TIS11, complete cds.

BI303379

Tumor necrosis factor receptor superfamily, member $12 \mathrm{a}$

2.0

AF323608

Fibrinogen-like 2

2.0

NM_021744

CD14 antigen

Other functions

NM_017269

NM_012835

Protein tyrosine phosphatase, receptor type J (metabolism)

BI275741

Cortistatin (neurotransmitter)

Epithelial membrane protein 1 (cell surface molecule)

Unknown functions

AA874846

Transcribed sequences

AI406660

EST234947 normalized rat ovary, Bento Soares Rattus sp. cDNA clone

BF558056

ROVDV40 3' end, mRNA sequence

UI-R-C0-hj-e-12-0-UI.r1 UI-R-C0 Rattus norvegicus cDNA clone

AW915115

UI-R-C0- similarity hj-e-12-0-UI 5', mRNA sequence

BM385061

Lunatic fringe gene homolog (Drosophila)

Transcribed sequences

Snail homolog (Drosophila)

AA946199

UI-R-BJ2-bps-c-09-0-UI.s1 UI-R-BJ2 Rattus norvegicus cDNA clone

A

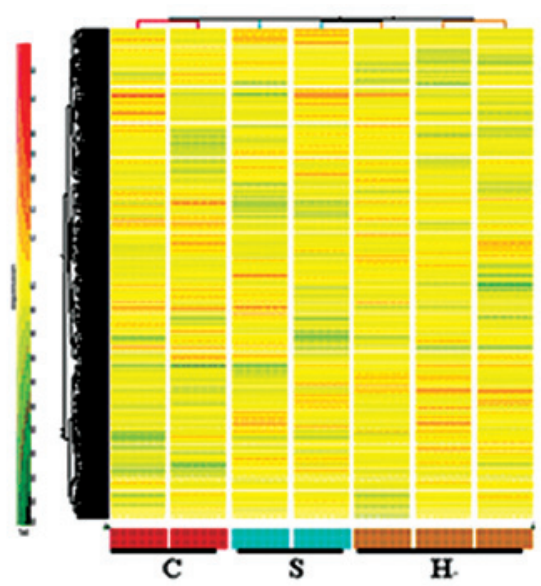

B

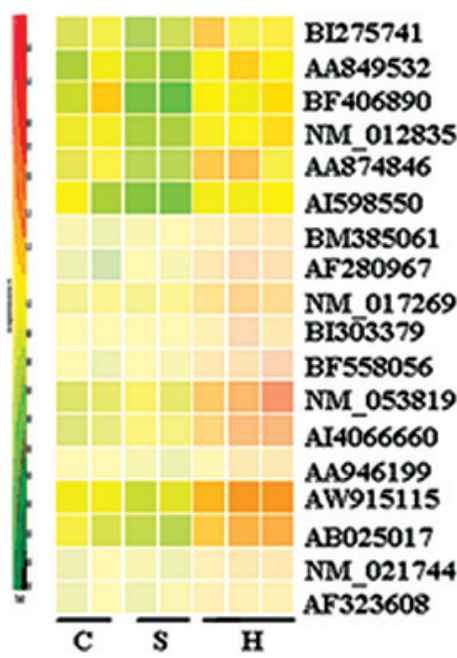

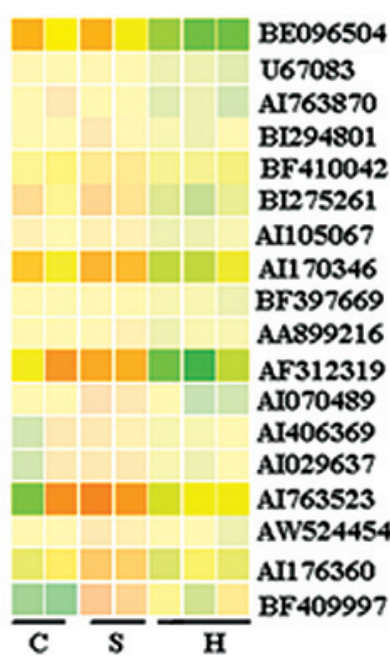

Figure 1. Hierarchical clustering analysis of all Affymetrix oligonucleotide microarray genes. (A) Cluster analysis demonstrating genes grouped according to their global expression profiles (19,174 genes) in rat cerebrum $2 \mathrm{~h}$ following 1-hemorrhage, followed by various treatments of three $\mathrm{SAH}$ (H) compared with two saline-operated controls (S) and two normal (C) specimens. (B) Hierarchical clustering graph of 18 upregulated (left) and 18 downregulated (right) genes. The selected genes displayed at least 1.5 -fold change between $\mathrm{H}$ and $\mathrm{S}$ specimens. The significantly different genes $(\mathrm{p}<0.05)$ between $\mathrm{C}$ and $\mathrm{S}$ specimens, and genes differentially expressed more than $25 \%$ in two S specimens were removed. Gene expression in all subsets of samples are displayed colorimetrically. The colors indicate the relative expression levels of each gene. Red indicates the highest expression above the median value and green indicates the lowest expression below the median value. Two C-, two S- and three H-related genes are indicated by their row numbers and gene name.

and for all five of these genes the fold changes obtained with real-time PCR were very similar to those obtained by microarray analysis. It was found that protein tyrosine phosphatase receptor type J, TNF receptor superfamily 
Table III. Differentially expressed downregulated genes in the subarachnoid hemorrage cerebrum.

\begin{tabular}{|c|c|c|}
\hline Accession no. & Gene description & Fold chang \\
\hline \multicolumn{3}{|l|}{ Other functions } \\
\hline AF312319 & $\gamma$-aminobutyric acid (GABA) B receptor, 1 (neurotransmitter) & -2.7 \\
\hline AI170346 & Cytochrome P450-like protein (protein metabolism/turnover) & -1.9 \\
\hline U67083 & KRAB-zinc finger protein (KZF)-2 (transcriptional regulator) & -1.8 \\
\hline AI763523 & Chloride channel 3 (chloride homeostasis) & -1.6 \\
\hline \multicolumn{3}{|c|}{ Unknown functions } \\
\hline AI070489 & Transcribed sequences & -3.1 \\
\hline BI275261 & $\begin{array}{l}\text { UI-R-CX0-bwr-d-11-0-UI.s1 UI-R-CX0 Rattus norvegicus cDNA clone } \\
\text { UI-R-CX0-bwr-d-11-0- UI 3', mRNA sequence }\end{array}$ & -2.6 \\
\hline AI029637 & $\begin{array}{l}\text { UI-R-C0-jg-a-09-0-UI.s1 UI-R-C0 Rattus norvegicus cDNA clone } \\
\text { UI-R-C0-jg-a-09-0-UI 3', mRNA sequence }\end{array}$ & -2.2 \\
\hline BF409997 & Transcribed sequences & -2.2 \\
\hline AI763870 & Transcribed sequences & -1.9 \\
\hline AI176360 & Similar to palmdelphin (LOC310811), mRNA & -1.9 \\
\hline AI105067 & $\begin{array}{l}\text { Similar to ADP-ribosylhydrolase like 1; -1.9 ADP-ribosylhydrolase } 2 \\
\text { (LOC290880), mRNA }\end{array}$ & -1.9 \\
\hline AI406369 & Similar to protein kinase nek1 (EC 2.7.1.-) - mouse (LOC290705), mRNA 9 & -1.8 \\
\hline BE096504 & Similar to hypothetical protein dJ465N24.2.1 (LOC362626), mRNA & -1.8 \\
\hline AW524454 & Similar to epithelial stromal interaction 1 , isoform a (LOC364433), mRNA & -1.8 \\
\hline AA899216 & Transcribed sequences & -1.7 \\
\hline BI294801 & Similar to SR rich protein (LOC297942), mRNA & -1.7 \\
\hline BF410042 & Transcribed sequences & -1.6 \\
\hline BF397669 & $\begin{array}{l}\text { UI-R-BS2-bed-c-02-UI.s1 UI-R-BS2 Rattus norvegicus cDNA clone } \\
\text { UI-R-BS2-bed-c-02-UI 3', mRNA sequence }\end{array}$ & -1.6 \\
\hline
\end{tabular}

member 12a, TIS11 complete code sequences, cortistatin and fibrinogen-like 2 did not show evident consistency between real-time PCR and the microarray data in SAH (Table IV). This may be explained by the varying detection ranges of the two techniques. The results of Fig. 2 revealed three marked upregulations, PGES, CD14 and TIMP1, and two marked downregulations, KZF-2 and GABA B receptor, in the $\mathrm{SAH}$ rat cerebrum.

Verification of altered expression of TIMP1, MMP2 and MMP9 by RT-PCR and Western blot analysis. We further investigated the roles of TIMP1 and MMP regulation in cerebrum pathophysiology of SAH. RT-PCR data revealed the altered expression of MMP2 and MMP9 (Fig. 3). The expression patterns of both TIMP-1 gene and protein were well matched with the expression profile obtained from the microarray analysis, supporting the validity of the data obtained from the microarray analysis. The quantitative data revealed that mRNA levels of only MMP9, and not MMP2, were differentially regulated in the SAH specimens. Therefore, MMP9/ TIMP1 expression is differentially regulated in acute activation of SAH.

\section{Discussion}

The present study was designed to gain insight into the early phase of SAH in a well-established 1-hemorrhage rat model

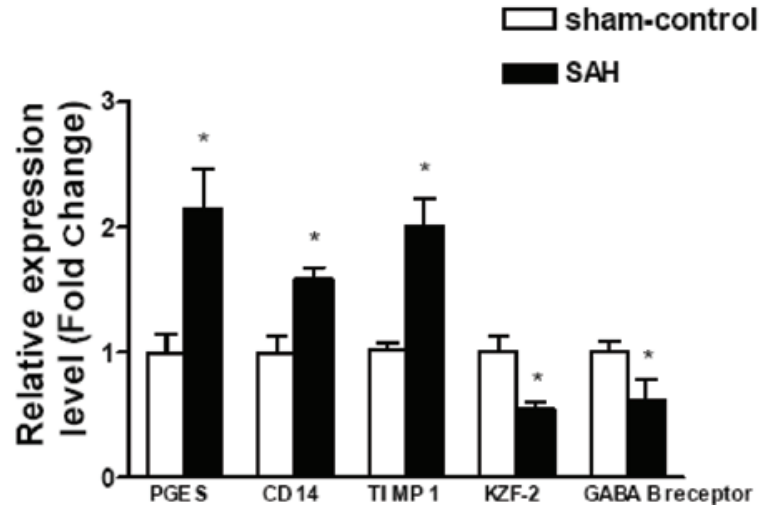

Figure 2. Confirmation of microarray results for three upregulated genes, PGES, CD14, TIMP1, and two downregulated genes, KZF-2, GABA B receptor, by real-time quantitative reverse transcription PCR. Real-time PCR analyses of differentially expressed genes involved in SAH microarray assay between sham-control rats (open bar) and SAH rats (black bar). Gene expression values were normalized to $\beta$-actin and were expressed relative to sham-operated values. Data are presented as the mean and SEM $(n=3)$. An asterisk denotes a significant difference from the respective sham-control at $\mathrm{p}<0.05$ (Student's t-test).

of brain injury. The 2-h time point that was selected was the clear choice to capture dynamic changes in mRNA regulation preceding the more pronounced functional changes that occur $24 \mathrm{~h}$ post-SAH $(1,12)$. This time point also matches the time 
Table IV. Comparison of microarray and real-time PCR expression for 10 selected genes in the subarachnoid hemorrhage specimens vs. the sham-control specimens.

\begin{tabular}{|c|c|}
\hline Accession no. & Gene description \\
\hline
\end{tabular}

Upregulated

AF280967

NM_021744

NM_053819

BI303379

AB025017

NM_012835

AF323608

NM_017269

Downregulated

U67083

AF312319
Prostaglandin E synthase

CD14 antigen

Tissue inhibitor of metalloproteinase 1

Tumor necrosis factor receptor superfamily, member $12 \mathrm{a}$

Rattus norvegicus gene for TIS11, complete cds

Cortistatin

Fibrinogen-like 2

Protein tyrosine phosphatase, receptor type J

KRAB-zinc finger protein (KZF)-2

$\gamma$-aminobutyric acid (GABA) B receptor, 1

$\begin{array}{rr}2.3 & 2.3 \\ 1.6 & 1.6 \\ 2.6 & 1.9 \\ 2.0 & 1.0 \\ & \\ 2.3 & 0.6 \\ 1.5 & 1.2 \\ 2.0 & 1.2 \\ 2.0 & 0.7 \\ & \\ -1.8 & -1.8 \\ -2.7 & -1.9\end{array}$

Data shown are fold changes in SAH $(\mathrm{H})$ relative to the saline-operated $(\mathrm{S})$ specimens from three determinations. Real-time PCR was standardized with $\beta$-actin expression.
A

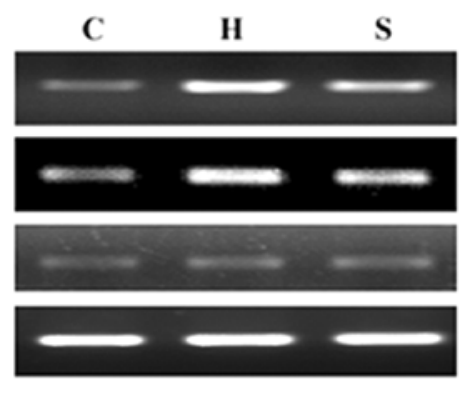

TIMP1

MMP9

MMP2

$\beta$-actin

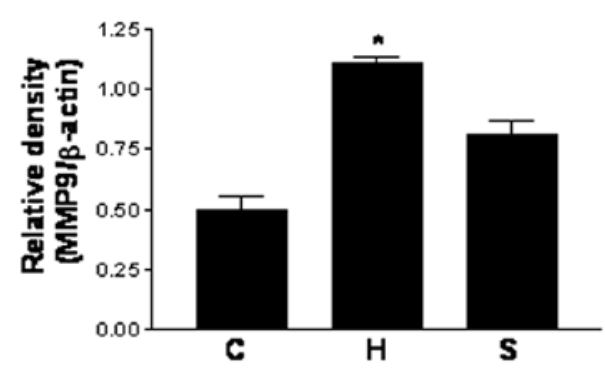

B

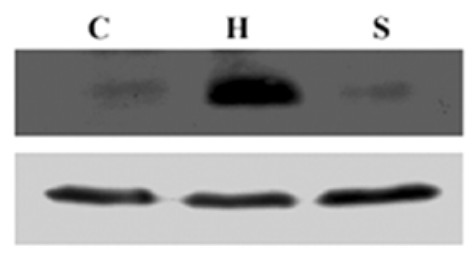

TIMP1

$\beta$ - actin
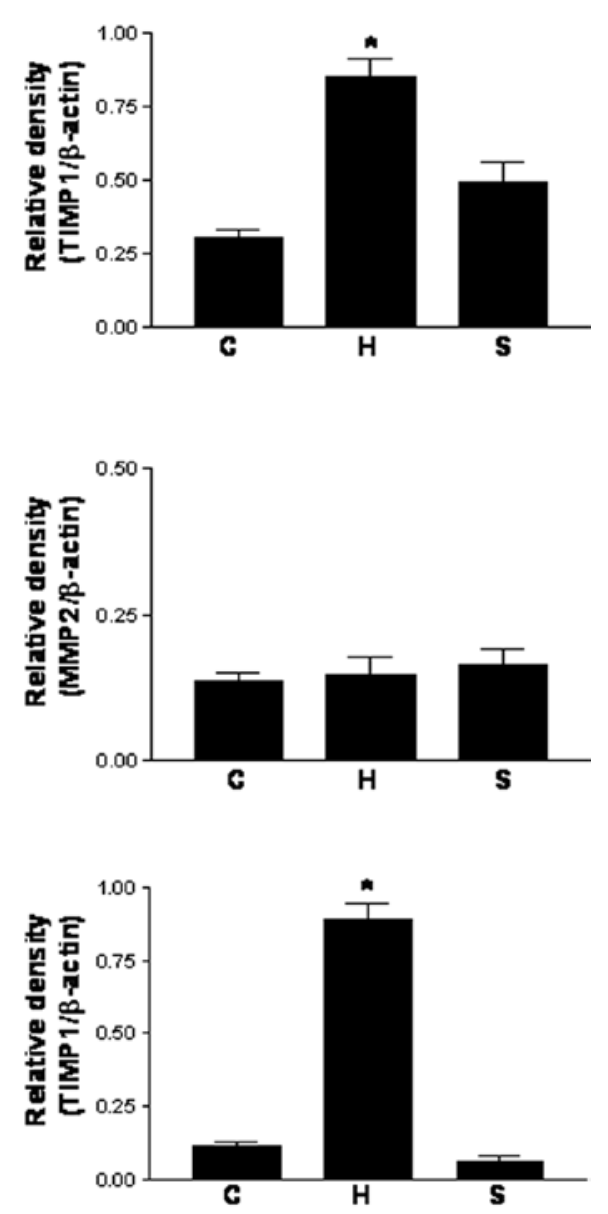

Figure 3. Expression of TIMP1, MMP2 and MMP9 in rat cerebrum following 1-hemorrhage. (A) Gene expression of TIMP1, MMP2 and MMP9 was analyzed by in SAH (H) compared with saline-operated controls (S) and normal (C) specimens using RT-PCR. Relative mRNA amount was expressed as the ratio between TIMP-1, MMP9, MMP2 and $\beta$-actin. (B) Protein expression of TIMP1 was analyzed using Western blot analyses. Relative protein amount was expressed as the ratio between TIMP-1 and $\beta$-actin. Data were expressed as the mean \pm SEM $(n=3)$. ${ }^{*} P<0.05$ versus $S$ (Student's t-test). 
course of an immediate global decrease in cerebral blood flow following SAH induction (13). In addition, in the experimental SAH rats we observed that the injected blood accumulated and compressed the whole brain tissue. Our microarray identification of 19,174 genes revealed 18 upregulated and 18 downregulated genes. None of the early genes, including jun and fos, known to be upregulated in stress conditions were identified in the microarray analysis. Notably, a little cluster of inflammation genes, including PGES, CD14 and TIMP1 were upregulated in the early phase of SAH. These results coincide with results of SAH-related inflammatory reactions in numerous studies reported in the literature $(14,15)$.

TIMP1 expression was differentially regulated in a markedly similar pattern to that of MMP9 in acute activation following $2 \mathrm{~h}$ of 1-hemorrhage cerebrum SAH, suggesting that an imbalance of MMP9/TIMP1 regulation is implicated in the acute phase of SAH. The elevated expression of TIMP1 along with MMP9 following acute SAH injury may reflect the fact that MMP inhibitors play a role in matrix remodeling at specific time points following brain injury. Recently, one study reported a model for astrocyte TIMP1 regulation in acute inflammation injury, where acute activation of neural cells (astrocytes, microglia and neurons) by pro-inflammatory cytokines may lead to enhanced levels of TIMP1 in the tissue microenvironment and may elicit a typical repair response early in injury (8). Our results appear to corroborate the hypothesis that in the early phase of SAH conditions, acute immune activation of the cerebrum increases TIMP1, which participates in a protective response and elicits repair as a balance mechanism. Of note, TIMP1 is induced in response to a number of pro-inflammatory stimuli, including cytokines activated following brain injury such as tumor necrosis factor (TNF)- $\alpha$, IL-1 or lipopolysaccharide (LPS) (16-18). Further studies are required to demonstrate whether the expression of these cytokines is concomitant with the upregulation of TIMP1 following inflammatory SAH injury.

Prostaglandins have been implicated in normal cellular processes and pathophysiological conditions, including inflammation, edema, bronchoconstriction and fever (19). PGES is a rate-limiting enzyme in prostanoid synthesis. The activity of mPGES-1 and COX-2, or coupling of COX-2 with mPGES-1, may contribute to the generation of pro-inflammatory PGE2 (20). The release of prostaglandins is part of the inflammatory response and may mediate tissue inflammation or anti-inflammatory effects (21). COX-2 expression was detected in basilar arterial tissue in both acute and chronic stages following SAH (22). Therefore, PGES may, in turn, produce sufficient quantities of eicosanoids to affect hemodynamics following SAH. Clearly, more research is required to elucidate the mechanisms by which the early immediate response genes promote the inflammatory response by the rapid and excessive production of prostaglandins, initiating an inflammatory cascade that is critical for survival following acute brain injury following SAH. According to the present data array, CD14 expression may contribute to prime and/or maintain microglial activation within the cerebrum and yield an exaggerated immune response that could be potentially active for certain cytokines, including TNF- $\alpha$ and their receptors, such as TNF receptor superfamily member $12 \mathrm{a}$, one of the founding genes of this present data array. However, the role of CD14 within the brain cells following SAH still needs be investigated.

In our series, two downregulated genes, KZF-2 and GABA $B$ receptor, were verified and related to the $\mathrm{SAH}$ process. Members of the $\mathrm{C} 2 \mathrm{H} 2$ zinc finger transcription factor family, such as KZF-2, play key roles in the regulation of cell proliferation, differentiation and apoptosis in response to a variety of stimuli $(23,24)$. The metabotropic GABA B receptors are coupled to $G$ proteins and modulate synaptic transmission through intracellular effector systems of the mammalian central nervous system (25). GABA B receptors function by inhibiting presynaptic transmitter release or by increasing the potassium conductance responsible for long-lasting inhibitory postsynaptic potentials $(26,27)$. However, the mechanisms leading to decreased $\mathrm{KZF}-2$ and GABA $\mathrm{B}$ receptor expression in SAH have not yet been characterized.

In conclusion, our microarray evidence reveals that the activation of inflammatory cascades following SAH is a complex systemic response. Further studies should verify whether the novel gene expression profiles of MMP9/TIMP1 co-regulate PGES induction of the inflammation pathway through CD14. Targeting these inflammatory mediators of systemic inflammation associated with SAH could be a promising therapeutic strategy.

\section{Acknowledgements}

This study was supported by 95-2745B-37-003-URD; 96-2320B-037-004; 97-2745-B-037-005 (Taiwan) to Yi-Ren Hang and 95-2314-B-037-005-URD; 95-2314-B-037-050-MY2; 97-2314-B037-013; KMUH98-8R02 (Taiwan) to Shen-Long Howng.

\section{References}

1. Kim DE, Suh YS, Lee MS, Kim KY, Lee JH, Lee HS, Hong KW and Kim CD: Vascular NAD(P)H oxidase triggers delayed cerebral vasospasm after subarachnoid hemorrhage in rats. Stroke 33: 2687-2691, 2002.

2. Lin CL, Jeng AY, Howng SL and Kwan AL: Endothelin and subarachnoid hemorrhage-induced cerebral vasospasm: pathogenesis and treatment. Curr Med Chem 11: 1779-1791, 2004.

3. Sehba FA, Schwartz AY, Chereshnev I and Bederson JB: Acute decrease in cerebral nitric oxide levels after subarachnoid hemorrhage. J Cereb Blood Flow Metab 20: 604-611, 2000.

4. Vikman P and Edvinsson L: Gene expression profiling in the human middle cerebral artery after cerebral ischemia. Eur J Neurol 13: 1324-1332, 2006.

5. Lu A, Tang Y, Ran R, Ardizzone TL, Wagner KR and Sharp FR: Brain genomics of intracerebral hemorrhage. J Cereb Blood Flow Metab 26: 230-252, 2006.

6. Vikman P, Beg S, Khurana T, Hansen-Schwartz J and Edvinsson L: Gene expression and molecular changes in cerebral arteries following subarachnoid hemorrhage in the rat. J Neurosurg 105: 438-444, 2006.

7. Crocker SJ, Pagenstecher A and Campbell IL: The TIMPs tango with MMPs and more in the central nervous system. J Neurosci Res 75: 1-11, 2004.

8. Gardner J and Ghorpade A: Tissue inhibitor of metalloproteinase (TIMP)-1: the TIMPed balance of matrix metalloproteinases in the central nervous system. J Neurosci Res 74: 801-806, 2003.

9. Norenberg MD: Astrocyte responses to CNS injury. J Neuropathol Exp Neurol 53: 213-220, 1994.

10. Rivera S, Tremblay E, Timsit S, Canals O, Ben-Ari Y and Khrestchatisky M: Tissue inhibitor of metalloproteinases-1 (TIMP-1) is differentially induced in neurons and astrocytes after seizures: evidence for developmental, immediate early gene, and lesion response. J Neurosci 17: 4223-4235, 1997.

11. Horstmann S, Su Y, Koziol J, Meyding-Lamadé U, Nagel S and Wagner S: MMP-2 and MMP-9 levels in peripheral blood after subarachnoid hemorrhage. J Neurol Sci 251: 82-86, 2006. 
12. Endo H, Nito C, Kamada H, Yu F and Chan PH: Akt/GSK3beta survival signaling is involved in acute brain injury after subarachnoid hemorrhage in rats. Stroke 37: 2140-2146, 2006.

13. Prunell GF, Mathiesen T and Svendgaard NA: Experimental subarachnoid hemorrhage: subarachnoid blood volume, mortality rate, neuronal death, cerebral blood flow, and perfusion pressure in three different rat models. Neurosurgery 52: 165-175, 2003.

14. Dumont AS, Dumont RJ, Chow MM, Lin CL, Calisaneller T, Ley KF, Kassell NF and Lee KS: Cerebral vasospasm after subarachnoid hemorrhage: putative role of inflammation. Neurosurgery 53: 123-133, 2003.

15. Provencio JJ and Vora N: Subarachnoid hemorrhage and inflammation: bench to bedside and back. Semin Neurol 25: 435-444, 2005

16. Aihara Y, Kasuya H, Onda H, Hori T and Takeda J: Quantitative analysis of gene expressions related to inflammation in canine spastic artery after subarachnoid hemorrhage. Stroke 32: 212-217, 2001.

17. Bugno M, Witek B, Bereta J, Bereta M, Edwards DR and Kordula T: Reprogramming of TIMP-1 and TIMP-3 expression profiles in brain microvascular endothelial cells and astrocytes in response to proinflammatory cytokines. FEBS Lett 448: 9-14, 1999.

18. Lee WJ, Shin CY, Yoo BK, Ryu JR, Choi EY, Cheong JH, Ryu JH and Ko KH: Induction of matrix metalloproteinase-9 (MMP-9) in lipopolysaccharide-stimulated primary astrocytes is mediated by extracellular signal-regulated protein kinase 1/2 (Erk1/2). Glia 41: 15-24, 2003.

19. Murakami M, Nakatani Y, Tanioka T and Kudo I: Prostaglandin E synthase. Prostaglandins Other Lipid Mediat 68-69: 383-399, 2002 .
20. Giannico G, Mendez M and LaPointe MC: Regulation of the membrane-localized prostaglandin E synthases mPGES- 1 and mPGES-2 in cardiac myocytes and fibroblasts. Am J Physiol Heart Circ Physiol 288: H165-H174, 2005.

21. Takayama K, Garcia-Cardena G, Sukhova GK, Comander J, Gimbrone MA and Libby P: Prostaglandin E2 suppresses cytokine production in human macrophages through the EP4 receptor. J Biol Chem 277: 44147-44154, 2002.

22. Osuka K, Suzuki Y, Watanabe Y, Takayasu M and Yoshida J: Inducible cyclooxygenase expression in canine basilar artery after experimental subarachnoid hemorrhage. Stroke 29: 1219-1222, 1998.

23. Gebelein B, Fernandez-Zapico M, Imoto M and Urrutia R KRAB-independent suppression of neoplastic cell growth by the novel zinc finger transcription factor KS1. J Clin Invest 102: 1911-1919, 1998.

24. Mazarakis N, Michalovich D, Karis A, Grosveld F and Galjart N: Zfp-37 is a member of the KRAB zinc finger gene family and is expressed in neurons of the developing and adult CNS Genomics 33: 247-257, 1996.

25. Kornau HC: GABA(B) receptors and synaptic modulation. Cell Tissue Res 326: 517-533, 2006.

26. Jasmin L, Rabkin SD, Granato A, Boudah A and Ohara PT: Analgesia and hyperalgesia from GABA-mediated modulation of the cerebral cortex. Nature 424: 316-320, 2003.

27. Kuner R, Kohr G, Grunewald S, Eisenhardt G, Bach A and Kornau HC: Role of heteromer formation in GABA-B receptor function. Science 283: 74-77, 1999. 